\title{
ASO Visual Abstract: Comparison of Outcomes for Classic-Type Lobular Carcinoma In Situ Managed with Surgical Excision After Core Biopsy Versus Observation
}

\author{
Regina Matar, MD ${ }^{1}$, Varadan Sevilimedu, MBBS, DrPH ${ }^{2}$, Anna Park, PA ${ }^{1}$, Tari A. King, MD $^{3}$, and \\ Melissa Pilewskie, MD $^{1}$ \\ ${ }^{1}$ Breast Service, Department of Surgery, Memorial Sloan Kettering Cancer Center, New York, NY; ${ }^{2}$ Biostatistics Service, \\ Department of Epidemiology and Biostatistics, Memorial Sloan Kettering Cancer Center, New York, NY; ${ }^{3}$ Department of \\ Breast Surgery, Dana Farber/Brigham and Women's Cancer Center, Boston, MA
}

As presented in our article (https://doi.org/10.1245/s10 434-021-10828-y), the 5-year cancer development rate in women with classic-type lobular carcinoma in situ (LCIS) on core biopsy is similar whether managed by surgical excision or observation; these data support the safety of omitting routine surgical excision following core biopsy diagnosis of classic-type LCIS.

\section{Comparison of Outcomes for Classic-Type Lobular Carcinoma In Situ} Managed With Surgical Excision After Core Biopsy vs. Observation

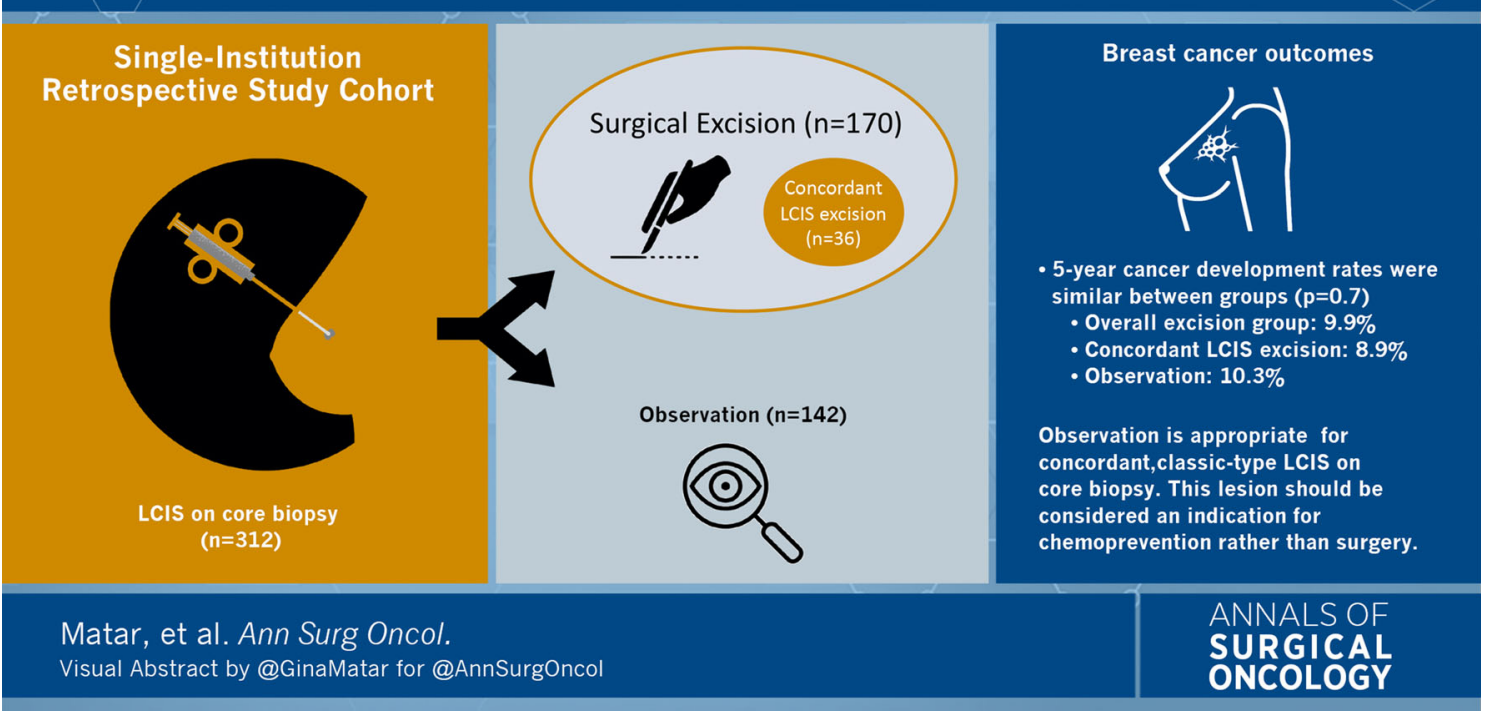

(C) Society of Surgical Oncology 2021?

M. Pilewskie, MD

e-mail: pilewskm@mskcc.org

Publisher's Note Springer Nature remains neutral with regard to jurisdictional claims in published maps and institutional affiliations. 